\section{Kontrastmittelallergie: Hauttests sinnvoll}

\author{
Überempfindlichkeitsreaktionen auf jodierte Kontrastmittel \\ sind nicht selten. Eine europäische Studiengruppe hat nun den \\ prädiktiven Wert von Hauttestungen überprüft.
}

\begin{abstract}
A llergologen aus zwölf europäischen Studienzentren testeten bis $\mathrm{zu} 13$ Kontrastmittel bei 220 Personen mit vorangegangener Überempfindlichkeitsreaktion auf ein jodiertes Kontrastmittel. Das Ereignis musste mindestens eine Woche zurückliegen, im Median lag zwischen Reaktion und Hauttests ein halbes Jahr. Als Kontrollen dienten 71 noch nicht mit Kontrastmitteln in Kontakt gekommene Personen und elf Probanden,
\end{abstract}

die bisher Kontrastmittel gut toleriert hatten. Die Tests bestanden aus Pricktest, Intrakutantest und Patchtest.

Die Hauttestspezifität lag zwischen 96 und 100\%. Optimal war ein Zeitraum von zwei bis sechs Monaten zwischen Reaktion und Test, dann reagierten jeweils bis zu 50\% der zuvor bereits von einer Überempfindlichkeitsreaktion Betroffenen auf den Hauttest positiv. Bei vorangegangener Soforttypreaktion er-

Tabelle. Reaktionen bei Kontrastmittelüberempfindlichkeit bei 220 Patienten

$\begin{array}{lcc}\text { Symptom } & \text { Soforttyp }<\mathbf{1} \mathbf{h}(\mathbf{\%}) & \text { Nicht-Soforttyp }>\mathbf{1} \text { h (\%) } \\ \text { Urtikaria } & 33 & 19 \\ \text { Angioödem } & 25 & 24 \\ \text { Exanthem } & 12 & 67 \\ \text { Erythem } & 11 & 9 \\ \text { Dyspnoe } & 30 & 7 \\ \text { Übelkeit/Erbrechen } & 18 & 6 \\ \text { Blutdruckabfall } & 16 & 0 \\ \text { Kollaps } & 11 & 3\end{array}$

\title{
$\operatorname{lgG}_{4}$ als Marker für Toleranzentwicklung
}

\section{Viele Kinder mit Ekzemen und einer nachweisbaren Sensibilisierung gegen Nahrungsmittel vertragen diese Substanzen später wieder problemlos. Dabei scheinen die spezifischen $\operatorname{lgG}_{4}$-Antikörper für die Toleranzentwicklung prognostisch relevant zu sein.}

chwedische Forscher bezogen 123

Kinder unter zwei Jahren, die an Ekzemen litten, in ihre Studie ein. Bei 60 der 89 gegen Ei oder Milch sensibilisierten Kinder konnte im Provokationstest eine Nahrungsmittelallergie bestätigt worden. Diesen Kindern wurde eine Eliminationsdiät empfohlen. 24 Kinder reagierten allein positiv auf $\mathrm{Ei}$, elf nur auf Milch und 25 auf beide Allergene.

In einer aktuell vorgelegten Publikation bewerteten die Autoren Testergebnisse zum Zeitpunkt des Studieneinschlusses und im Alter von 4,5 Jahren: Im Alter von 4,5 Jahren konnten $37 \mathrm{zu}$ - vor gegen Ovalbumin sensibilisierte Kinder wieder Ei essen sowie 28 der kleinen Milchallergiker wieder Milch trinken und wurden daher als tolerant eingestuft. Von den übrigen reagierten im Alter von 4,5 Jahren noch sieben auf Ei, zwei auf Milch und vier auf beide Allergene.

Die Kinder mit Toleranzentwicklung hatten bei Studieneinschluss höhere $\mathrm{IgG}_{4}$-Antikörpertiter gegen Ovalbumin bzw. $\beta$-Laktoglubulin aufgewiesen als die Kinder, die später weiter auf Ei oder Milch reagierten. Auch das Verhältnis von spezifischen $\mathrm{IgG}_{4}$ - zu IgE-Antikör- wies sich der Intradermaltest als die sensitivste Untersuchung. Bei Nicht-Soforttypreaktionen (> $1 \mathrm{~h}$ ) musste das späte Ablesen des Intradermaltests mit einem Patchtest kombiniert werden, um eine ausreichende Sensitivität zu erreichen.

Die vor einer Kontrastmittelgabe übliche Frage nach bisher schon aufgetretenen Reaktionen scheint nach den Studiendaten für eine Risikoabschätzung nicht ausreichend: Knapp die Hälfte der Probanden hatte eine allergische Reaktion auf das Kontrastmittel entwickelt, ohne vorher jemals ein solches erhalten zu haben.

Fazit: Hauttestungen mit jodierten Kontrastmitteln zeigen eine hohe Spezifität und ermöglichen bei rund 50\% der Patienten den Nachweis einer immunologischen Überempfindlichkeitsreaktion. Die Autoren dieser Studie empfehlen Hauttestungen als geeignete Maßnahme, um das Risiko einer Kontrastmittelreaktion besser abschätzen zu können. $f k$

Brockow K et al. Skin testing in patients with hypersensitivity reactions to iodinated contrast media - a European multicenter study. Allergy 2009; 64: 234-41

pern war bei Kindern mit späterer Toleranzentwicklung höher. Am höchsten war dieser Quotient bei den Kindern, die initial zwar zirkulierende IgE-Antikörper gegen Ei oder Milch aufgewiesen, aber im Hauttest nicht positiv reagiert hatten. Die Eliminationsdiät beeinflusste diesen Antikörperquotienten über einen Zeitraum von sechs Wochen weder im Serum noch im Speichel.

Fazit: Entgegen früherer Studien ist nach dieser Untersuchung nicht das spezifische IgE, sondern das spezifische $\mathrm{IgG}_{4}$ bzw. das Verhältnis von $\mathrm{IgG}_{4} \mathrm{zu}$ IgE der beste Prädiktor für eine Toleranzentwicklung bei früher Nahrungsmittelsensibilisierung.

$f k$

Tomičić S et al. High levels of IgG $\mathrm{I}_{4}$ antibodies to foods during infancy are associated with tolerance to corresponding foods later in life. Pediatr Allergy Immunol 2009; 20: 35-41 